\title{
SOME ASPECTS OF QUANTITATIVE ANALYSIS OF TERNARY ALLOYS OF GROUP III-NITRIDES BY AUGER ELECTRON SPECTROSCOPY
}

\author{
Jozef LIDAY ${ }^{*}$ - Peter VOGRINČIČ ${ }^{*}$ - Gernod ECKE ${ }^{* *}$
}

\begin{abstract}
In this work, the quantities have been determined experimentally that are needed for reliable and precise quantitative interpretation of Auger spectra of nitrides $\mathrm{AlN}$, GaN and of their ternary alloys $\mathrm{Al}_{x} \mathrm{Ga}_{1-x} \mathrm{~N}$. Measurements of reference samples AlN and GaN under various parameters of the primary electron beam (energy 3 and $5 \mathrm{keV}$, beam incidence angle with respect to the surface normal $12.5^{\circ}$ and $45^{\circ}$ ) and of the ion beam (energy 0.5 and $1.0 \mathrm{keV}$, beam incidence angle with respect to the surface normal $67.5^{\circ}$ and $35^{\circ}$ ) allowed to find the elemental sensitivity factors for these nitrides, and measurements on reference samples of ternary alloys $\mathrm{Al}_{x} \mathrm{Ga}_{1-x} \mathrm{~N}$ allowed to find the component sputtering yields $Y_{\mathrm{Ga}} / Y_{\mathrm{Al}}$. To the best of our knowledge there is a lack of such data for those materials in the literature.
\end{abstract}

K e y w ords: GaN, AlN, $\mathrm{Al}_{x} \mathrm{Ga}_{1-x} \mathrm{~N}$, AES relative elemental sensitivity factors, component sputtering yields

\section{INTRODUCTION}

In recent years, much attention has been paid to semiconductor materials based on group III nitrides and their alloys used as short wavelength light emitting materials. The properties of these materials are tightly related to their chemical composition. One of these materials is also the alloy of $\mathrm{Al}$ and $\mathrm{Ga}$ nitrides, $\mathrm{Al}_{x} \mathrm{Ga}_{1-x} \mathrm{~N}$. To determine the elemental composition and its depth distribution, Auger electron spectroscopy (AES) is one of the most widely used techniques. Even though depth profiling using AES is already a standard process, there are still fields in which a further development is needed. One of them is accurate quantitative evaluation of Auger spectra in the case of nanometer thin film structures based on chemical compounds such as GaN, other group III/nitrides and their alloys.

Whereas in the analysis of homogeneous alloys the accuracy of quantitative AES is relatively good, problems are encountered in analysis of compounds because in general the shape of Auger peaks is changed in comparison with the pure element. Hence, the quantities needed to evaluate elemental concentrations (Auger current and elemental sensitivity factors) cannot be determined from the amplitude of the Auger peaks but from the area below the peaks in $N(E)$ spectra $[1,2]$. Other phenomena affecting the accuracy of quantitative analysis are the changes in morphology, structure and initial composition in the surface region caused by bombarding the surface by high energy ions used for depth profiling. To cope with this adverse fact it is necessary to know the changes induced by ions directly in the particular analysed material. These changes depend on both the parameters of the ion beam (energy, kind of ions, angle of incidence) and the analysed material itself and are the result of preferential sputtering (component sputtering yields) and other effects induced by interaction of the ion beam with the solid [3, 4]. From among the various methods for determining the component sputtering yields, the most reliable quantitative results could by obtained using standard samples of comparable composition.

If AES analysis involves sputtering and if the same experimental parameters are used in sputtering both the analysed and reference samples, then the experimentally determined elemental sensitivity factors account also for the component sputtering yields.

For correct quantitative interpretation of spectra of chemical compounds and of their alloys it is necessary to have the relative sensitivity factors of elements and the sputtering yields measured for the material under analysis [5]. So far only scanty data have been published on these quantities for aluminium, gallium and their alloys [6] and they do not cover the required range of experimental parameters needed for wider utilization in experimental practice. The topic of this work has been experimental determination of the quantities needed for reliable and precise quantitative interpretation of the measured Auger spectra of materials based on gallium and aluminium nitrides and their ternary alloys. Relative elemental sensitivity factors and component sputtering yields have been measured of the components contained in these multicomponent materials.

\section{EXPERIMENTAL}

The fundamental condition for conducting this study is the existence of reference samples of known composition, thus of gallium and aluminium nitrides ( GaN and

\footnotetext{
* Institute of Electronics and Photonics, Slovak University of Technology, Ilkovičova 3, 81219 Bratislava, Slovakia; ${ }^{* *}$ Centre for Microand Nanotechnologies, Technical University of Ilmenau, Gustav Kirchhoff-Str. 7, D-98693 Ilmenau, Germany.
} 
Table 1. AlN, GaN and $\mathrm{Al}_{x} \mathrm{Ga}_{1-x} \mathrm{~N}$ samples with known composition used to find the relative elemental sensitivity factors and component sputtering yields in the ternary system $\mathrm{Al}_{x} \mathrm{Ga}_{1-x} \mathrm{~N}$

\begin{tabular}{|c|c|c|c|}
\hline sample & $\mathrm{x}$ in $\mathrm{Al}_{x} \mathrm{Ga}_{1-x} \mathrm{~N}$ & deposition & laboratory \\
\hline 108 & 1 & MOCVD & ZMN, Ilmenau \\
\hline 59 & 0.13 & MOCVD & JKU, Linz \\
\hline 163 & 0.16 & MOCVD & ZMN, Ilmenau \\
\hline 96 & 0.19 & MOCVD & JKU, Linz \\
\hline 322 & 0.23 & MOCVD & ZMN, Ilmenau \\
\hline 167 & 0.27 & MOCVD & ZMN, Ilmenau \\
\hline 29 & 0.31 & MOCVD & JKU, Linz \\
\hline 174 & 0.35 & MOCVD & ZMN, Ilmenau \\
\hline 827 & 0.48 & MOCVD & ZMN, Ilmenau \\
\hline 267 & 0 & MOCVD & ZMN, Ilmenau \\
\hline 218 & 0 & MOCVD & ZMN, Ilmenau \\
\hline
\end{tabular}

Table 2. Experimental conditions of the measurements

\begin{tabular}{cccc}
\hline $\begin{array}{c}\text { Primary } \\
\text { electron } \\
\begin{array}{c}\text { beam energy } \\
(\mathrm{keV})\end{array}\end{array}$ & $\begin{array}{c}\text { Primary } \\
\text { electron beam } \\
\text { incidence angle } \\
\left({ }^{\circ}\right)\end{array}$ & $\begin{array}{c}\text { Sputtering } \\
\text { ion beam } \\
\text { energy } \\
(\mathrm{keV})\end{array}$ & $\begin{array}{c}\text { Angle } \\
\text { of ion beam } \\
\text { incidence } \\
\left({ }^{\circ}\right)\end{array}$ \\
\hline 3 & 12.5 & 0.5 & 67.5 \\
3 & 12.5 & 1.0 & 67.5 \\
5 & 12.5 & 0.5 & 67.5 \\
5 & 12.5 & 1.0 & 67.5 \\
3 & 45 & 0.5 & 35 \\
3 & 45 & 1.0 & 35 \\
5 & 45 & 0.5 & 35 \\
5 & 45 & 1.0 & 35 \\
\hline
\end{tabular}

$\mathrm{AlN}$ ) and of their alloys with various contents of respective constituents $\mathrm{Al}$ and $\mathrm{Ga}\left(\mathrm{Al}_{x} \mathrm{Ga}_{1-x} \mathrm{~N}\right)$. The used samples have been prepared by metal-organic chemical vapour deposition (MOCVD) in two various laboratories, see Tab. 1. Their stoichiometry (composition of the $\mathrm{Al}_{x} \mathrm{Ga}_{1-x} \mathrm{~N}$ layers) was established by $\mathrm{X}$-ray diffraction and spectroscopic ellipsometry. In the end, a stripe of pure copper with a thickness of approximately $500 \mathrm{~nm}$ was deposited on each sample. This served as a reference material and at the same time it prevented charging in the course of sample analysis and sputtering.

AES measurements were carried out in a Varian Auger electron spectrometer equipped with a cylindrical mirror analyzer and an EX 05 VG ion gun. The energy spectra of the emitted electrons were measured in the differentiated mode $E^{*} \mathrm{~d} N(E) / \mathrm{d} E$. A primary electron beam was used with energy $3 \mathrm{keV}$ and $5 \mathrm{keV}$ and angles of incidence $12.5^{\circ}$ and $45^{\circ}$ with respect to the surface normal. Sputtering was achieved by a scanned $\mathrm{Ar}^{+}$ion beam with energies $0.5 \mathrm{keV}$ and $1 \mathrm{keV}$ and angles of incidence $67.5^{\circ}$ and $35^{\circ}$ with respect to the surface normal. The energy resolution of the CMA was $\Delta E / E=0.3 \%$. Auger depth profiling employed the Auger peaks of Al (KLL), Ga (LMM) and N (KLL).

At present, many authors use the peak areas as well as peak-to-peak heights as a measure of Auger currents. The latter method is more usual in the case of alloys. In our study we used the Auger peak-to-peak heights
(APPH) for quantitative interpretation of Auger spectra. Such an approximation of Auger current can be used in the analysis of GaN and AlN and of their alloys because the relative sensitivity factors are measured directly on reference samples of GaN and $\mathrm{AlN}$, and in the ternary alloy no additional change in the shapes of the Auger peaks is observed in comparison with their shapes in GaN and AlN.

The quantification procedures for the binary semiconductors GaN, AlN and then for the $\mathrm{Al}_{x} \mathrm{Ga}_{1-x} \mathrm{~N}$ material system were carried out for the two different employed primary electron energies $(3 \mathrm{keV}, 5 \mathrm{keV})$, two ion beam energies $(0.5 \mathrm{keV}, 1.0 \mathrm{keV})$, two angles of incidence of the primary electron $\left(12.5^{\circ}\right.$ and $\left.45^{\circ}\right)$ and of the ion sputtering $\left(67.5^{\circ}\right.$ and $\left.35^{\circ}\right)$ beams. The experimental set-ups lead to the following experimental parameters, see Table 2 .

\section{RESULTS}

\subsection{Relative sensitivity factors for AlN and GaN}

The relative sensitivity factors for aluminium, gallium and nitrogen were determined from measuring clean $\mathrm{AlN}, \mathrm{GaN}$ and $\mathrm{Cu}$ samples under various experimental conditions (Tab. 1). Measurement of each sample consisted of three steps: first it was measured at the place of the deposited layer of pure copper, then in the layer of $\mathrm{Al}_{x} \mathrm{Ga}_{1-x} \mathrm{~N}$ itself and at the end again in the place of pure copper. The relative sensitivity factors were then determined with respect to the $\mathrm{Cu}$ (LMM) peak, while taking the average value of the two measurements on $\mathrm{Cu}$. The APPHs in differentiated spectra were processed in a standard way [7] taking into account the matrix correction factors, namely the back scattering factor, $r$, the atomic densities, and the attenuation lengths of Auger electrons, $\lambda$. The values of the backscattering factor were calculated using the relations of Shimizu [8], the attenuation lengths of Auger electrons were determined by the TPP-2M formulae [9] and after Jablonski [10]. The found relative sensitivity factors for Ga (LMM), Al (KLL) and $\mathrm{N}$ (KLL) in GaN and AlN for various experimental parameters are summarized in Tab. 3.

The results reveal a marked difference in the relative sensitivity factors for the peak of $\mathrm{N}$ (KLL) in AlN and in GaN. This is primarily a consequence of the different value of preferential sputtering of components of AlN and GaN.

\subsection{Preferential sputtering of single elements in the $\mathbf{A l}_{x} \mathbf{G a}_{1-x} \mathbf{N}$ system}

For determining the component sputtering yields in the $\mathrm{Al}_{x} \mathrm{Ga}_{1-x} \mathrm{~N}$, reference samples of nitrides $\mathrm{Al}_{x} \mathrm{Ga}_{1-x} \mathrm{~N}$ with known composition were used as listed in Tab. 1. From the measured values of the APPHs in differentiated spectra, the surface concentration of single elements in $\mathrm{Al}_{x} \mathrm{Ga}_{1-x} \mathrm{~N}$ were calculated using the relative sensitivity factors of the particular ternary system shown 
Table 3. Relative elemental sensitivity factors of Al (KLL) and N (KLL) in AlN and Ga (LMM) and N (KLL) in GaN

\begin{tabular}{cccccc}
\hline $\begin{array}{c}\text { Primary } \\
\text { electrons }\end{array}$ & $\begin{array}{c}\text { Sputtering } \\
\text { ions }\end{array}$ & $\begin{array}{c}\text { Al (KLL) } \\
\text { in AlN }\end{array}$ & $\begin{array}{c}\text { N (KLL) } \\
\text { in AlN }\end{array}$ & $\begin{array}{c}\text { Ga (LMM) } \\
\text { in GaN }\end{array}$ & $\begin{array}{c}\text { N (KLL) } \\
\text { in GaN }\end{array}$ \\
\hline $3 \mathrm{keV}, 12.5^{\circ}$ & $0.5 \mathrm{keV}, 67.5^{\circ}$ & 0.360 & 0.405 & 0.566 & 0.317 \\
$3 \mathrm{keV}, 12.5^{\circ}$ & $1.0 \mathrm{keV}, 67.5^{\circ}$ & 0.339 & 0.388 & 0.536 & 0.293 \\
$5 \mathrm{keV}, 12.5^{\circ}$ & $0.5 \mathrm{keV}, 67.5^{\circ}$ & 0.481 & 0.331 & 0.579 & 0.260 \\
$5 \mathrm{keV}, 12.5^{\circ}$ & $1.0 \mathrm{keV}, 67.5^{\circ}$ & 0.439 & 0.311 & 0.560 & 0.245 \\
$3 \mathrm{keV}, 45^{\circ}$ & $0.5 \mathrm{keV}, 35^{\circ}$ & 0.381 & 0.427 & 0.504 & 0.292 \\
$3 \mathrm{keV}, 45^{\circ}$ & $1.0 \mathrm{keV}, 35^{\circ}$ & 0.333 & 0.416 & 0.483 & 0.239 \\
$5 \mathrm{keV}, 45^{\circ}$ & $0.5 \mathrm{keV}, 35^{\circ}$ & 0.541 & 0.348 & 0.524 & 0.225 \\
$5 \mathrm{keV}, 45^{\circ}$ & $1.0 \mathrm{keV}, 35^{\circ}$ & 0.458 & 0.329 & 0.488 & 0.183 \\
\hline
\end{tabular}

Table 4. Experimental conditions of the measurements

\begin{tabular}{cc}
\hline Ion beam & $Y_{\mathrm{Ga}} / Y_{\mathrm{Al}}$ \\
experimental condition & for $\mathrm{Al}_{x} \mathrm{Ga}_{1-x} \mathrm{~N}$ \\
$67.5^{\circ}, 0.5 \mathrm{keV}, \mathrm{Ar}$ & 1.5 \\
$67.5^{\circ}, 1.0 \mathrm{keV}, \mathrm{Ar}$ & 1.55 \\
$45^{\circ}, 0.5 \mathrm{keV}, \mathrm{Ar}$ & 1.4 \\
$45^{\circ}, 1.0 \mathrm{keV}, \mathrm{Ar}$ & 1.45 \\
\hline
\end{tabular}

in Tab. 3. Due to different sputtering yields, the composition of the surface layer of the sample is changed during bombarding the sample by ions in comparison with the bulk composition. Using the relation for a twocomponent system [11] we determined the component sputtering yields of $Y_{\mathrm{Ga}} / Y_{\mathrm{Al}}$ from the measured surface concentration and the known bulk composition of the reference samples. The component sputtering yields characterize preferential sputtering of these elements in the ternary system $\mathrm{Al}_{x} \mathrm{Ga}_{1-x} \mathrm{~N}$. Table 4 lists the component sputtering yields $Y_{\mathrm{Ga}} / Y_{\mathrm{Al}}$ for $\mathrm{Al}_{x} \mathrm{Ga}_{1-x} \mathrm{~N}$ for various experimental parameters.

\section{CONCLUSIONS}

Relative sensitivity factors have been determined for elements contained in AlN and GaN nitrides by measuring the reference samples under various parameters of the electron and ion beams. By measuring the reference samples of ternary alloys of $\mathrm{Al}_{x} \mathrm{Ga}_{1-x} \mathrm{~N}$ under the same experimental conditions as those used while measuring AlN and GaN, the component sputtering yield $Y_{\mathrm{Ga}} / Y_{\mathrm{Al}}$ has been determined. The obtained values of the relative sensitivity factors and the component sputtering yields have been verified on applying them to the analysis of ternary alloys of $\mathrm{Al}_{x} \mathrm{Ga}_{1-x} \mathrm{~N}$ of known composition.

\section{Acknowledgement}

The work was supported by the Scientific Grant Agency of the Ministry of Education of the Slovak Republic and of the Slovak Academy of Sciences No. 1/0779/10.

\section{REFERENCES}

[1] SEAH, M. P.: Quantification in AES and XPS, In: Practical Surface Analysis by Auger and X-Ray Photoelectron Spec- troscopy (D. Briggs and M.P. Seah, eds.), Wiley, Chichester, 1990.

[2] LIDAY, J.-HOFMANN, S.-HARMAN, R.: Quantitative Auger Electron Analysis of Homogeneous Binary Alloys of Cr, Fe and Ni, Vacuum 43 (1992), 331-339.

[3] HOFmanN, S.: Compositional Depth Profiling by Sputtering, Prog. Surf. Sci. 36 (1991), 35-87.

[4] GNASER, H.: Low-Energy Ion Irradiation of Solid Surfaces, Series: Springer Tracts in Modern Physics, vol. 146, Springer, Berlin, 1999.

[5] TOUGARD, S.: Quantification of Nanostructures by Electron Spectroscopy, In: Surface Analysis by Auger and X-ray Photoelectron Spectroscopy (D. Briggs and J.T. Grant, eds.), IM Publications, Chichester, 2003.

[6] LIDAY, J.-ECKE, G.-BAUMANN, T.-VOGRINČIČ, P.BREZA, J.: Contribution to the Quantitative Analysis of Ternary Alloys of Group III Nitrides by Auger Spectroscopy, J. Electrical Eng. 61 (2010), 62-64.

[7] ZE-JUN, D.-SHIMIZU, R.: Surface analysis by Auger and X-Ray Photoelectron Spectroscopy, IM Publications 61 (2003), 587-618.

[8] SHIMIZU, R.: Quantitative Analysis by Auger Electron Spectroscopy, Jpn. J. Appl. Phys. 22 (1983), 1631-1642.

[9] TANUMA, S.-POWELL, C. J.-PENN, D. R. : Calculation of Electron Inelastic Mean Free Paths II. Data for 27 Elements over the $502000 \mathrm{eV}$ Range, Surf. Interface Anal. 17 (1991), 911-926.

[10] JABLONSKI, A.: Remarks on the Definition of the Backscattering Factor in AES, Surf. Sci. 499 (2002), 219-228.

[11] SHIMIZU, H.-ONO, M.-NAKAYAMA, K.: Quantitative Auger Analysis of Copper-Nickel Alloy Surfaces After Argon Ion Bombardment, Surf. Sci. 36 (1973), 817-821.

Received 12 March 2011

Jozef LIDAY (Assoc Prof, PhD) graduated in solid state physics in 1968 and received his $\mathrm{PhD}$ in electronics and vacuum technology, both from STU, in 1985. His teaching and research activities include materials analysis, thin films and surface science.

Peter VOGRINČIČ (Ing), graduated in radio-electronics from the Slovak University of Technology in 1992. He is engaged in research, particularly in Auger analysis and depth profiling.

Gernot ECKE (Dr, Ing) was born in Calbe, Germany in 1958. He graduated in electronic devices from TU Ilmenau in 1983, and gained the PhD degree in 1986. Since that time he has been Assistant Professor. His teaching and research activities include surface science and materials analysis. 